\title{
A delimitação do corpus na pesquisa em jornalismo: o interdiscurso como método
}

\author{
SABRINA FRANZONI \\ Universidade do Vale do Rio dos Sinos (UNISINOS) - E-mail: sabrinafranzoni@yahoo.com.br \\ Professora do Curso de Jornalismo da UNISINOS. Doutora em Comunicação e Informação pela UFRGS. \\ Mestre em Sociologia Política e Especialista em Estudos do Jornalismo pela UFSC.
}

\begin{abstract}
Resumo
A operacionalização de um trabalho acadêmico está vinculada às opções teóricas e metodológicas. Por essa razão, este artigo propõe pensar o interdiscurso como método capaz de contribuir na delimitação do corpus em pesquisas no jornalismo que tenham o discurso como objeto. Apropria-se, então, da ideia de Maingueneau (2008), de que o interdiscurso precede o discurso, isto é, de que todo discurso recebe a própria identidade da presença, implícita ou polêmica, de um Outro. Como exemplo desse processo de circunscrição do objeto, elege-se a figura do ombudsman do jornal Folha de S. Paulo. Pelo viés apresentado, o discurso do ombudsman é compreendido como um conjunto de textos e dizeres inseridos no campo jornalístico, tensionado por outros discursos que o atravessam.
\end{abstract}

\section{Palavras-chave}

Jornalismo, interdiscurso, corpus, ombudsman, Folha de S. Paulo.

\begin{abstract}
The operationalization of an academic work is connected to the theoretical and methodological options available. For this reason, this article suggests the idea of the interdiscourse as a method capable of contributing in the corpus delimitation in researches, in the journalism field, which have the discourse as their object. Therefore, this study appropriates Maingueneau's ideia of the interdiscourse as preceding the discourse (2008), i.e., it considers that every discourse acquires its own identity through the presence of an Other. The ombudsman, from the newspaper Folha de S. Paulo, is selected as an example of the process leading to the object's circumscription. From this point of view, the ombudsman's discourse is comprehended as a collection of texts and sayings inserted in the journalistic field and also intertwined with other discourses which project it.
\end{abstract}

\section{Keywords}

Journalism, interdiscourse, Corpus, ombudsman, Folha de S. Paulo.

Artigo recebido em 13/04/2013

Aprovado em 21/06/2013 
delimitação do corpus em uma pesquisa não é uma tarefa fácil,
principalmente porque essa discussão está vinculada às opções teóricas e
metodológicas, definidoras da operacionalização de um trabalho tido como científico $^{1}$. Diante desta dificuldade, este artigo quer refletir sobre como o pesquisador constrói seu corpus, atendo-se a trabalhos que tomam o discurso como objeto analítico. Para isso, propõe-se pensar a unidade de análise como um espaço de trocas entre os vários discursos que foram acolhidos pelo pesquisador, iniciando, assim, a seleção, pelo material que irá compor sua historicidade, para, posteriormente, chegar até aos textos e dizeres identificados com uma determinada posição discursiva.

Para desenvolver esta reflexão, apropria-se da ideia de Maingueneau (2008, p. 20) de que o "interdiscurso tem precedência sobre o discurso", isto é, entende que o autor propõe apreender o discurso através do interdiscurso, construindo um sistema no qual a definição de rede semântica que circunscreve a especificidade de um discurso coincide com a definição das relações desse discurso com o seu outro. Esta hipótese, apresentada no livro Gênese dos discursos, se materializa na noção de interdiscurso: na relação entre os textos, em sua materialidade discursiva, nas mudanças históricas e nos discursos que as constituem. Pensada desse modo, a reflexão sobre o interdiscurso contribui para problematizar o corpus de pesquisa, isto é, para assinalar as fronteiras estabelecidas pelo discurso do ombudsman. Assim, busca-se estabelecer uma coerência interna a partir de uma oposição entre o discurso do ombudsman da Folha de S. Paulo e de outros discursos que tensionem com ele (e não com todos os outros que tratam do tema ombudsman). Essa coerência, para fins de delimitação, é percebida dentro de um determinado campo discursivo.

Para dar conta dessa construção do corpus através do interdiscurso, Maingueneau (2008) propõe um sistema de restrições semânticas globais. O caráter "global" dessa semântica se manifesta no fato de que ela restringe simultaneamente o conjunto dos "planos" discursivos, tanto do vocabulário quanto dos temas tratados, da

1 Sobre os parâmetros para elaboração de um trabalho científico ver DEMO (2009) e SANTOS (1989). 
intertextualidade ou das instancias de enunciação. Nessa lógica, o discurso deixa de ser pensado como um conjunto de textos e passa a ser visto como uma prática discursiva. Assim, para o teórico francês, "O sistema de restrições semânticas, para além do enunciado e da enunciação, permite tornar esses textos comensuráveis com a 'rede institucional' de um 'grupo', aquele que a enunciação discursiva ao mesmo tempo supõe e torna possível" (MAINGUENEAU, 2008, p. 22-23).

Elegeu-se a figura do ombudsman de imprensa, como um exemplo, buscando mapear, nos elementos de sua historicidade, aqueles textos e dizeres que o vinculam ao campo jornalístico e, mais especificamente, ao jornal Folha de S. Paulo. É importante frisar, desde o início, que, no processo de pesquisa, se lida com conjuntos textuais diversos, produzidos por vários autores, durante longos períodos e com gêneros também distintos. Por essa razão, adotar o viés de Maingueneau, que liga a problemática da gênese e a interdiscursividade, torna possível enfrentar essa tarefa sem ser obrigado a empobrecer a complexidade textual, pois, para o autor, "o interesse de tais corpos de referência reside justamente em sua diversidade" (MAINGUENEAU, 2008, p.29).

Há que se entender que a perspectiva defendida por Maingueneau (2008) segue a tendência das novas abordagens da análise do discurso no estabelecimento do corpus de pesquisa ou "corpora". Da facilidade metodológica oferecida por um corpus construído como conjunto de dados prévios, feito de discursos em contraste, produto de

2 Mazière (2007) explica como seu deu o processo de transição na $\mathrm{AD}$, da definição do corpus de pesquisa. Segundo a autora, os primeiros corpora estudados foram textos políticos e textos fundadores: "As técnicas de segmentação são então aplicadas a um conjunto de textos selecionados para significar por contraste: político, de gênero, diacrônico. [...] A partir de temas neutralizados, analisavam-se discursos contrastados. Havia, portanto, uma dupla ruptura: com o texto e com o conteúdo como tema. A ideia de condições de produção estáveis e homogêneas estava então calcada sobre a problemática das situações de comunicação, mesmo que a $\mathrm{AD}$ tenha herdado mais a noção do marxismo que a comunicação, ainda pouco pensada no início dos anos 1960. Depois, os corpora foram construídos em uma heterogeneidade ampliada, por meio de um processo co-extensivo à análise, por um "trajeto temático" traçado no arquivo, por uma abertura aos fragmentos do cotidiano, por uma confrontação via informática com os "grandes corpora" que abandonavam a montagem para voltar à antologia. Paralelamente, a questão dos objetos e de gêneros restabelecia novas homogeneidades" (MAZIÈRE, 2007, p. 58-60). Foi somente a partir da década de 1980 é que o corpus passa a ser construído no decorrer da pesquisa, dentro de uma rede de memória. 
condições de produção controláveis, a Análise do Discurso, a $\mathrm{AD}^{3}$, passa a procedimentos de construção de sequências discursivas ligadas a uma "rede de memória". Mazière (2007) esclarece que a "palavra-tema" (termo-pivô), eleita pelo saber anterior do analista, as condições de produção, anteriores à produção, a escolha dos textos a segmentar, escolhidos desde o princípio, dão lugar a uma construção dinâmica de corpus, móvel, gerida em interação com a progressão da análise. Daí é que, segundo a autora, vem essa nova noção de "estado de corpus", surgida em 1980, resultado de uma hipótese transitória emitida pelo analista.

Inicialmente, para tratar a série de "estados de corpus" considerada como resquício de uma prática de pesquisa, Mazière (2007) explica que são necessárias transformações tecnológicas que incrementem tanto as capacidades de processamento quanto os meios de coleta. O estudo a partir do "estado de corpus" retoma o arranjo de algoritmos da $\mathrm{AD}$ a serviço de um dispositivo algorítmico evolutivo ramificado. É preciso conduzir o trabalho sem recorrer a "metatermos" lógicos (do tipo daqueles que organizam a base do conhecimento) que mascaravam a materialidade das estruturas significantes, porque, para Pêcheux (1995), a análise de discurso consiste em considerar as estruturas significantes como "coisas" (com tudo o que esse termo implica de referência ao efeito de acaso).

Dessa forma, o corpus transformado em rede de memória se torna uma espécie de "dicionário discursivo" que integra continuamente o efeito das aberturas, das reconfigurações e das mudanças de "estado do corpus" ao longo da análise. As construções dos discursos incluiriam as maneiras de falar e as esquematizações. Simultaneamente, essa "rede de memória" deveria, no curso da escrita da análise, construir novos enunciados, abrindo novas regiões do corpus. Assim, para Mazière (2007, p.62), essa construção supõe "renunciar ao sonho de uma interpretação fechada garantida por uma leitura explicitada em proveito de uma leitura-escrita e de uma política de interpretação que se basearia na avaliação das forças de interpretação em

3 Este trabalho aborda a Análise do Discurso (AD) sob o enfoque de linha francesa. 
uma conjuntura". Nessa nova abordagem, o corpus não é mais um conjunto estanque de textos, é um conjunto sem fronteira no qual o interdiscurso, exterior, irrompe no intradiscurso, interior.

O relato inicial, ao mesmo tempo em que apresenta a justificava do porquê de acionar a concepção de Maingueneau (2008), aponta para uma opção metodológica que permite ao pesquisador criar sua própria rede de memória, a partir de um corpus de pesquisa construído como um processo e não mais como algo que já esteja préelaborado ou que seja imutável. A contribuição para as pesquisas, no jornalismo, que tenham análise discursiva como foco, está justamente na possibilidade de traçar pontes entre um discurso específico, aqui tomado como o do ombudsman, dado numa certa situação, por exemplo, a coluna na Folha de S. Paulo, e inserido em um campo determinado, nesse caso o jornalístico, com outros discursos, presentes e ou silenciados nele mesmo.

\section{O campo: jornalismo e AD}

Ao compreender o jornalismo como um lugar de circulação e produção de sentidos, Benetti (2007, p.107) o define de forma sucinta "como um discurso: a) dialógico; b) polifônico; c) opaco; d) ao mesmo tempo efeito e produtor de sentidos; e) elaborado segundo condições de produção próprias e rotinas particulares". Para esta autora, a Análise do Discurso seria especialmente produtiva ao estudar o jornalismo especificamente em duas direções: o mapeamento de vozes e a identificação de sentidos:

$\mathrm{O}$ primeiro tipo de pesquisa para o qual a $\mathrm{AD}$ é um método adequado diz respeito à análise dos sentidos do discurso jornalístico. É preciso visualizar a estrutura do texto, compreendendo que esta estrutura vem 'de fora': o texto é decorrência de um movimento de forças que lhe é exterior e anterior. O texto é a parte visível ou material de um processo altamente complexo que inicia em outro lugar: na sociedade, na cultura, na ideologia, no imaginário. A conjunção de forças que compõem o texto nem sempre é aparente - diríamos mesmo que raramente é visível por si mesma, e só o método arqueológico do analista do discurso pode evidenciar esta origem. (BENETTI, 2007, 
Essa reflexão, sobre a identificação de sentidos e o mapeamento de vozes, contribui para pensar a construção do discurso jornalístico em sua materialidade e exterioridade e este artigo perpassa o primeiro enquadramento, ao delimitar a análise sobre o ombudsman.

Além disso, é importante frisar que a $\mathrm{AD}$ não trata da língua em si, mas do discurso. "E a palavra discurso, etimologicamente, tem em si a ideia de curso, de percurso, de correr, de movimento. O discurso é assim palavra em movimento" (ORLANDI, 2000, p.15). A AD leva em consideração a exterioridade como constitutiva do discurso, assim como a historicidade e a ideologia. A ligação da materialidade do texto com a sua exterioridade indica que a ideia de um "texto original" é imaginária, pois existem vários textos possíveis num mesmo texto, e o mesmo se estendendo para os discursos. Por outro lado, isso não significa que, para os analistas do discurso, seja possível considerar que um texto ou um discurso possa tomar qualquer direção. Caso contrário, a relação com a exterioridade não existiria.

Assim, podemos dizer que é o pesquisador "quem", ao selecionar o(s) texto(s) - no caso do discurso aqui examinado, o do ombudsman - faz a relação da materialidade com a exterioridade. O texto, segundo Orlandi, é visto como uma unidade complexa e heterogênea: "a AD está assim interessada no texto não como objeto final de sua explicação, mas como unidade que lhe permite ter acesso ao discurso. O trabalho do analista é percorrer a via pela qual a ordem do discurso se materializa na estruturação do texto" (ORLANDI, 1996, p.14). Para o analista do discurso, o(s) texto(s), apesar de em sua apresentação ter(em) um começo, um meio e um fim, como discurso é(são) incompleto(s), não é(são) fechado(s), pois tem(têm) relação com outros textos, com suas condições de produção, ou com o que a AD chama de sua exterioridade constitutiva: o interdiscurso, a memória do dizer.

A respeito da definição de interdiscurso e memória discursiva (ou do dizer), 
Augustini (2007), traz para o debate questionamentos pertinentes, nos quais faz uma diferenciação entre o interdiscurso como o lugar de todo dizer "[...] um espaço mais amplo, onde coexistem todos os dizeres, os possíveis e os impossíveis, os que já foram ditos e os que ainda não foram ditos" e o de memória discursiva, "que por sua vez, é um recorte desse espaço, ela é a responsável pela relação entre um determinado conjunto de sentidos e as suas respectivas formações discursivas. Do todo, apenas alguns sentidos são ativados dentro de uma FD: é nesse processo de ativação que trabalha a Memória Discursiva" (AUGUSTINI, 2007, p.304).

No caso do texto específico, escrito por um ombudsman, existe uma relação explícita com outros textos, pois o objetivo do jornalista que ocupa essa função é justamente criticar, destacar, elogiar aquilo que é produzido, pela própria publicação, ou pelo compartilhamento com outros sujeitos que trabalham com ele, e que têm seus textos publicados no mesmo "espaço" onde ele escreverá seu comentário. Esses outros textos também têm relação com a exterioridade (os acontecimentos, os entrevistados, os leitores etc). Consequentemente, a relação dos textos do ombudsman com a exterioridade é muito forte.

Assim, inserir, neste artigo, o debate da relação entre os vários textos e vozes que atravessam o discurso jornalístico, elaborado por esse profissional, é pensar em uma troca interdiscursiva, contemplando, ao mesmo tempo, o caráter dialógico desse discurso. Para Maingueneau (2008), essa reflexão passa por afirmar a existência de uma exterioridade que não apenas repercute no texto, mas que, de fato, o constitui, e que não pode ser dele apartada. Com isso, esse autor propõe apreender "de uma só vez" o discurso através do interdiscurso, reflexão realizada na sequência, que contribui para problematizar a delimitação e abrangência do corpus de pesquisa.

\section{O primado do interdiscurso}

Maingueneau (2008) propõe que a unidade de análise não seja o discurso, mas 
o espaço de trocas entre vários discursos convenientemente escolhidos e isto implica em colocar o interdiscurso $^{\text {4iv }}$ como o espaço de regularidade pertinente, do qual diversos discursos seriam apenas componentes. Para o autor, a identidade interdiscursiva é que estruturaria a identidade de um discurso, hipótese resumida como o "primado do interdiscurso". Nessa perspectiva, de uma "heterogeneidade constitutiva", Maingueneau (2008, p.31), “amarra, em uma relação inextricável, o Mesmo do discurso e seu Outro". Dessa forma, o discurso do ombudsman da Folha de S. Paulo somente é percebido de uma determinada maneira por oposição a um outro, que seja distinto dele, mas que ao mesmo tempo esteja presente nele, nem que seja pela ausência.

O que se percebe, desde o inicio, ao descrever a ação metodológica a partir do interdiscurso, é a necessidade premente de se fazer escolhas, sejam elas de discursos, sejam de formações discursivas, isto é, de núcleos de sentidos. Pode-se afirmar que é no interior do campo discursivo que se constitui um discurso, sendo assim, essa constituição, em hipótese, pode deixar-se descrever em termos de operações regulares sobre formações discursivas já existentes. Isso não significa, entretanto, que um discurso específico constitua da mesma maneira em todos os discursos desse campo, pois não é possível determinar, a priori, quais modalidades (confronto aberto, aliança, neutralidade aparente, etc.) se estabelecem entre as diversas formações discursivas nesse espaço. Assim, será o analista, diante do seu propósito, quem irá proceder a uma separação, no campo, de subconjuntos de formações discursivas julgados relevantes para colocar em relação.

As hesitações que aparecerem na determinação dos componentes pertinentes ao espaço discursivo não são somente retóricas. Maingueneau (2008) esclarece que se pode achar que basta considerar qual(is) outro(s) discurso(s) do campo é(são) citado(s) e

4 Maingueneau (2008, p. 34) define o interdiscurso "pela substituição de uma tríade: universo discursivo (o conjunto de formações discursivas de todos os tipos que interagem numa conjuntura dada), campo discursivo (define apenas uma extensão máxima, o horizonte a partir do qual serão construídos domínios suscetíveis de ser estudados) e espaço discursivo (conjunto de formações discursivas que se encontram em concorrência, delimitam-se reciprocamente em uma região determinada do universo discursivo.[...] Esse recorte em campos não define zonas insulares; é apenas uma abstração necessária, que deve permitir abrir múltiplas redes de troca." 
recusado(s) pelo discurso "segundo" para identificá-los como o(s) discurso(s) "primeiro(s)" através do(s) qual(is) aquele(s) se constituem. De fato, essas polêmicas explícitas não são um sintoma seguro, e pode-se muito bem supor que a relação constitutiva é marcada apenas por poucos índices na superfície discursiva. Sobre esse ponto, interessa apreender, apenas em última instância, a consideração dos fundamentos semânticos do discurso.

Esses fundamentos semânticos relacionam-se diretamente com o reconhecimento do primado do interdiscurso, pois constroem um sistema no qual a definição de rede semântica que circunscreve a especificidade de um discurso coincide com a definição das relações desse discurso com seu Outro. Maingueneau (2008) define esse Outro como o interdito de um discurso:

A formação discursiva, ao delimitar a zona do dizível legítimo, atribuiria por isso mesmo ao Outro a zona do interdito, isto é, do dizível faltoso. Se, no universo do gramaticalmente dizível, um discurso define uma ilhota de enunciados possíveis considerados capazes de saturar a enunciação a partir de uma posição dada, no conjunto de enunciados assim recusados, ele define igualmente um território como sendo o de seu Outro, daquilo que, mais do que qualquer outra coisa, não pode ser dito. $\mathrm{O}$ outro circunscreve justamente o dizível insuportável sobre cujo interdito se constitui o discurso; por conseguinte, não há necessidade de dizer, a cada enunciação, que ele não admite esse Outro, que exclui pelo simples fato de seu próprio dizer. (MAINGUENEAU, 2008, p.37)

O espaço discursivo tem, então, um duplo estatuto: pode-se apreendê-lo como um modelo dissimétrico ${ }^{5}$, que permite descrever a constituição de um discurso, mas também como um modelo simétrico, de interação conflituosa entre dois discursos, para

5 A explicação da dissimetria entre discurso primeiro e segundo, essencial para a compreensão do espaço discursivo é detalhada por Maingueneau (2008), na página 40, de Gênese dos discursos: "a dissimetria ligada à ordem da gênese não recobre a totalidade das relações entre discurso primeiro e discurso segundo; este último não faz desaparecer instantaneamente aquele do qual deriva, e pode inclusive acontecer que ele não o faça desaparecer de todo. Esse período de coexistência de uma duração variável é acompanhado de conflitos mais ou menos abertos. Quando se observa esse período, deve-se fazer abstração da dissimetria cronológica: o conflito confronta dois discursos do mesmo campo e não poderia, nesse nível, levar em conta uma dissimetria genética (MAINGENEAU, 2008, 40). 
os quais o outro representa, totalmente ou em parte, o seu referente. É esse último aspecto, o de um processo de dupla tradução, que vai nos interessar essencialmente, pois se o discurso segundo não tem mais nada a ver com o discurso primeiro, nem por isso ele necessariamente deixa de ter relação com as estruturas semânticas correspondentes, nas quais continuará a ler a figura de seu Outro (MAINGENEAU, 2008).

Destaca-se que um discurso segundo é derivável, regularmente de um ou de vários outros do campo discursivo. A semântica discursiva não poderá explicar por que foi esse discurso, e não outro, que se constituiu, mas, por outro lado, poderá tentar justificar a quais restrições está submetida tal constituição. De fato, tudo depende da definição do discurso que se acolhe. O discurso sempre se confunde com sua emergência histórica, com o espaço discursivo no interior do qual se constitui, com as instituições através das quais se desenvolveu, com os isomorfismos em cuja rede ele foi envolvido. Se uma dessas condições faltar, a identidade de uma posição enunciativa, no caso aqui a do ombudsman, corre o risco de se diluir, tornando mais difícil circunscrever o objeto a ser pesquisado.

\section{A historicidade}

Desenvolve-se, a seguir, um exercício de construção do objeto, iniciando pela reflexão em torno do contexto histórico da figura do ombudsman e busca-se, ao mesmo tempo em que se mapeiam os elementos de sua historicidade, isto é, os textos e dizeres que o vinculam ao campo jornalístico, ou mais especificamente, ao jornal Folha de $S$. Paulo, promover uma reflexão que caracterize o como dessa construção. A ideia é dialogar com o processo de construção do corpus, indicando, sempre que possível, de que maneira o interdiscurso é acionado.

Contextualizar historicamente o objeto a ser pesquisado é, antes de tudo, um ato de "reprodução construída", como explica o teórico Pedro Demo (2009), ao discorrer sobre a relação entre sujeito e objeto nas Ciências Sociais. Isto significa que 
não é possível descrever o surgimento da atividade de ombudsman ${ }^{6 \mathrm{vi}}$, na imprensa brasileira, ou, mais especificamente, dessa função, no jornal Folha de S. Paulo, sem um ponto de vista, sem que se tenha que fazer escolhas, ou melhor, seleções dos acontecimentos considerados relevantes.

Adota-se, então, as referências que situam esse acontecimento histórico tanto nas relações de poder quanto nas práticas sociais, isto é, em sua historicidade. Com isso, aponta-se, desde o início, que a narrativa a seguir é uma das leituras possíveis, efetivada por um sujeito inserido em determinadas condições sócio-históricas. Portanto, essa leitura expõe o aparato mobilizado pelo analista, que reconstrói a trajetória do ombudsman a partir do olhar do pesquisador, procurando pensar as condições de uma "enunciabilidade" passível de ser historicamente circunscrita (MAINGUENEAU, 2008).

Para isso, seleciona-se um conjunto de textos que possibilitem mapear trocas discursivas do ombudsman com seu "exteriorenunciativo", relacionando, ao mesmo tempo, enunciado e enunciação, discurso e interdiscurso, sem pretensões de totalidade e levando em consideração, também, que somente uma parte do dizível estará acessível a ser observada. Aglutinam-se, sob esse viés, três materiais: (1) as colunas dos ombudsmen da Folha, publicadas entre 1989 e 2012, abrangendo 11 mandatos. Optouse por restringirem-se as primeiras e as últimas colunas semanais de cada um dos profissionais, perfazendo um montante de 21 colunas e 36 textos, por serem

6 A organização Mundial de Ombudsmen de Imprensa (Organization of News Ombudsmen) aprovou, em 1982, as diretrizes que descrevem as funções deste profissional. "Os objetivos de um ombudsman de jornal devem se: aperfeiçoar a equidade, exatidão e responsabilidade do jornal, aumentar sua credibilidade, empenhar-se para melhorar a sua qualidade, tornar o jornal consciente das preocupações e problemas das comunidades por ele servidas. Os deveres do ombudsman devem incluir: funcionar como crítico interno, representar o leitor que tem reclamações, sugestões, questões ou cumprimentos, investigar todas as queixas e recomendar ação corretiva quando for o caso, alertar o diretor de Redação sobre todas as queixas, fazer conferência ou escrever para o público sobre as linhas, as posições e as atividades do jornal, defender o jornal, publicamente ou em particular, quando for o caso. Alguns meios dos quais o ombudsman dispõe para chegar a seus objetivos e cumprir suas tarefas incluem: uma coluna, memorandos internos, reuniões com equipes, questionamentos, conferências" (cf. http://www.infi.net/ono/).

7 Maingueneau $(2008$, p. 7) traz a noção de "exterior enunciativo" para referir-se à intertextualidade, buscando entender o discurso através do interdiscurso, problematizando a gênese e a interdiscursividade. 
representativas do lugar de fala: uma, de chegada, coloca as expectativas e, a outra, de saída, avalia as atividades do mandato. (2) os 34 trabalhos acadêmicos encontrados no Banco de Teses da Capes, cadastrados entre 1992 a 2012, incluindo teses e dissertações, que versam sobre o tema ombudsman em diferentes áreas do conhecimento; e (3) os quatro documentos que compõem o Projeto Editorial da Folha, que criam condições para a inserção da função de ombudsman: a Folha depois da campanha das Diretas Já! (1984), o Projeto Editorial da Folha - 1985-1986 (1985), o Projeto Editorial da Folha - 1986-1987 (1986) e A Hora das reformas (1988).

Assim, após uma leitura flutuante sobre os 36 textos que compõem as 21 colunas fez-se um mapeamento de sequências discursivas e observou-se que: ora elas vinculam o discurso do ombudsman a uma normatização do fazer jornalístico e ora a uma posição de mediação ou de representação em relação aos leitores. Dessa maneira, pode-se desdobrar em dois pontos distintos os acontecimentos em torno da historicidade do ombudsman: primeiro, em relação a sua origem escandinava, que o reconhece como uma instituição da burocracia do estado moderno, criado para ouvir as queixas individuais e controlar os atos da administração pública, e, em segundo, em relação ao jornalismo, no qual atua como um profissional, inserido num projeto de modernização tecnológica e editorial da Folha de S. Paulo, cuja função é receber as críticas dos leitores. Essas considerações iniciais permitem aproximar e distanciar, numa dinâmica de mescla, os dizeres e textos, e problematizar a interdiscursividade presente nas colunas do ombudsman.

Tem-se, então, como primeiro núcleo gerador de sentidos, a origem escandinava do ombudsman, função que surge, oficialmente na Lei Constitucional da Suécia, em 6 de junho de 1809. É a partir dessa perspectiva que outros sentidos serão acionados e ou rejeitados: 1- O ombudsman sueco é considerado uma instituição da burocracia do estado moderno; 2- Ele é um funcionário escolhido pelo Parlamento para fiscalizar o serviço público; 3- Ele é um Corregedor Administrativo; 4- Ele recebe queixas individuais dos cidadãos; 5- Sua função não tem caráter coercitivo. 
Os sentidos apontados acima podem ser identificados no texto de Leite (1975), que considera o ombudsman:

[...] um agente independente, sem subordinação hierárquica, com amplos poderes para apurar, fora dos métodos e processos burocratizados, falhas de administração pública e encaminhar solução para elas, é a tentativa de criar uma fórmula através da qual as queixas individuais sejam ouvidas, não pelo corpo burocrático, mas por um indivíduo sem vinculação ao sistema, e que possa indicar soluções, quando elas se imponham. (LEITE, 1975, p.14)

Acionados por Leite (1975), os sentidos irão, ao mesmo tempo, compor e orientar, agregar e excluir. Por exemplo, o conjunto dos textos que tratam da origem escandinava do ombudsman pode ajudar na delimitação daquilo que pode e deve ser dito neste núcleo, definindo assim, uma possível Formação Discursiva ${ }^{\text {8viii }}$. Com isso, é possível estabelecer uma rede de relações em torno da origem escandinava, o primeiro eixo, que deixa antever ou não, sua conexão com o que se considera, neste artigo, o segundo eixo gerador de sentidos.

Esse segundo núcleo de sentido aglutina-se nas relações do ombudsman com o jornalismo. Para isso, definiu-se, primeiro, como objeto, o ombudsman no Brasil. Esse deslocamento atrela o ombudsman ao projeto editorial da Folha de S.Paulo ${ }^{9}$, pois é a partir da implantação do "Projeto Folha"10", no final dos anos 80, que se desencadeia o processo que culmina, em 1989, com a criação do cargo de ombudsman.

A função do ombudsman "jornalista”, nessa segunda perspectiva, passa a ser

8 PÊCHEUX, (1995, p.160) "o sentido de uma palavra, de uma expressão, de uma proposição etc., não existe 'em si mesmo' (isto é, em sua relação transparente com a literalidade do significante), mas, ao contrário, é determinado pelas suas posições ideológicas que estão em jogo no processo sócio-histórico no qual as palavras, expressões e proposições são produzidas (isto é, reproduzidas). Dessa forma, o autor entende que as palavras, as proposições etc., mudam de sentido de acordo com as posições sustentadas por aqueles que as empregam em uma dada conjuntura.

9 Sobre a história e a formação do grupo Folha ver Paschoal (2007); Meloet al (2002) e Pilagallo (2002).

10 Silva (1988) contextualiza o "Projeto Folha" no livro Mil dias: os bastidores da revolução em um grande jornal. 
identificada com os seguintes discursos: 1- Representante do leitor; 2- Função inserida no projeto de modernização e humanização da Folha; 3- Profissional escolhido pela direção; 4- Independência de atuação para criticar o próprio jornal; 5- Recebedor de queixas individuais; 6- Função sem caráter coercitivo. Algumas dessas referências são encontradas na fala de Caio Túlio Costa, primeiro ombudsman da Folha, que conta o surgimento da função:

em 24 de setembro de 1989, finalmente, na sexta página, a Folha dava a resposta[referindo-se a uma placa que foi colocada ao lado da sala da direção, que ficou vazia por três meses, com os dizeres "ombudsman"], dando a luz a primeira coluna do seu ombudsman, intitulada Quando alguém é pago para defender o leitor, um profissional contratado para ouvir os leitores, além de expor o jornal publicamente a crítica. (COSTA 2006, p.8).

A fala de Caio Túlio Costa é tomada como exemplar, pois mescla tanto o discurso do profissional que ocupa a função de ombudsman, quanto a sua historicidade, que também é possível perceber no trecho a seguir, da primeira coluna, intitulada Quando alguém é pago para defender o leitor, publicada na Folha de S. Paulo, em 24 de setembro de 1989:

Começa aqui a coluna semanal do ombudsman da Folha. O nome pode parecer esquisito mas indica uma função que tem dado certo em outros países. Tanto na área pública (como na Suécia onde o ombudsman é uma espécie de ouvidor geral) quanto no jornalismo (como nos EUA, onde ele serve de advogado do leitor). No caso do ombudsman do "The Washington Post" (EUA) a sua coluna virou obrigatória. Ele anota os erros e às vezes até reescreve reportagens. Também aponta acertos e não se contenta em analisar apenas o "Post". Fala dos outros jornais e dos veículos. Faz "média criticam" a crítica da mídia.

É importante assinalar o paralelo entre algumas das atividades do ombudsman, no serviço público sueco, apesar de sua origem ter se dado há mais de um século, e as do ombudsman "jornalista”, surgido em 1989 no Brasil. Além disso, esses dois núcleos de sentidos propostos serão permeados e atravessados por outros discursos que extrapolam o campo jornalístico, como, por exemplo, alguns trabalhos do Banco de 
Teses da Capes, pesquisas desenvolvidas nas áreas das Ciências Jurídicas, onde o tema do ombudsman está relacionado ao papel das Ouvidorias Públicas ${ }^{11 x i}$ e é entendido como instrumento de aprimoramento da democracia (COIMBRA, 2007; NASSIF, 2007); ou, ainda, pesquisas relacionadas à área da Administração, nas quais os textos de análise aparecem direcionados para a inserção "estratégica" do ombudsman na relação da empresa com seus públicos (LAROCCA, 2004; ROCHA, 2007).

Entende-se que a partir do entrelaçamento de uma perspectiva discursiva com outras, que servem de referendo ou de contraponto, é possível tecer uma rede, na qual os fios vão se amarrando no contexto histórico, possibilitando delimitar o objeto, e, dessa forma, construir um corpus de pesquisa. Essa construção é feita pelas escolhas do pesquisador, que, na circunscrição de seu objeto, atua como uma espécie de gatekeeper contemporâneo, diante do material pesquisado e a partir dos critérios estabelecidos, mas que, também, permanece aberto ao imprevisível.

\section{Contribuições do Método}

Para finalizar, destacam-se algumas das contribuições metodológicas de Maingueneau que merecem serem retomadas. Entre elas, a necessidade de se fazer escolhas, a impossibilidade de análises totalizantes e a utilização das trocas interdiscursivas como ferramentas para pensar o contexto histórico. Além dessas, aponta-se a possibilidade de utilização de outras trocas, com materiais diversos.

11 Ora a função do ombudsman é comparada ao papel do promotor de Justiça, ora ao do Ministério Público (PARISI, 2001; RULLI NETO, 2007). É interessante destacar ainda que, em seu conjunto, as pesquisas, que tratam do tema, partem do paradigma do Estado Democrático de Direito, apontando a Constituição Federal de 1988 como um marco da consolidação da democracia no Brasil. Embora a Constituição de 1988 não tenha contemplado a instituição da Ouvidoria, ela abre margem para a necessidade de sua existência, segundo a pesquisa de mestrado de Moreira (2009), diante do dever da gestão pública de observar os princípios contidos no Artigo 37 da Constituição - que possibilitam ao cidadão, usuário dos serviços públicos, participar com reclamações, denúncias, críticas e sugestões. Outro trabalho aponta, ainda, que nesse período há um fortalecimento da democracia participativa na Europa e na América Latina, abrindo caminho para a criação de canais entre o cidadão e o poder público mediante mecanismos importantes de participação popular (GOMES, 2000). 
Percebe-se, ainda, nos dois exemplos apresentados sobre o ombudsman, que o discurso se confunde com sua emergência histórica, com o espaço discursivo no interior do qual a profissão se constitui, através das instituições nas quais se desenvolveu, e também com os isomorfismos em cuja rede foi envolvido. Maingueneau (2008), ao destacar a importância do interdiscurso, cria parâmetros que indicam a pertinência dessas condições se fazerem presentes na pesquisa, pois identifica na posição enunciativa as possibilidades de trocas intertextuais, o que torna exequível circunscrever o objeto, inclusive no campo do jornalismo.

Outra contribuição de Maingueneau (2008) que merece destaque é a constatação de que estamos 'condenados' a pensar em uma mistura inextricável do mesmo e do outro, numa rede de relações constantemente aberta, em movimentos que se entrecruzam em todos os sentidos, multiplicando dizeres, indefinidamente, em várias dimensões. Essa consideração desmistifica as propostas totalizantes, de hipótese que prevê em a captação das marcas textuais pela saturação ou que busquem uma apreensão absoluta do discurso. A multiplicação indefinida das fontes de pesquisa não pode ser tomada como um parâmetro de garantia de cientificidade de uma análise discursiva, mas fazer escolhas justificadas e manter as especificidades analíticas de cada texto e de cada discurso, através de um com e contra, de formações discursivas que sejam permeáveis, pode, sim, contribuir para certo rigor acadêmico.

A construção do corpus para o estudo do ombudsman, como objeto, requereu que fossem feitas escolhas anteriores (coleta de material) e posteriores (o que seria inserido), que sentidos fossem acionados, que alguns enunciados fossem recusados e outros incorporados. Enfim, construir o corpus e colocar em relação o discurso com seu Outro, o interdito e o dizer, a falta e o excesso, a afirmativa e o deslize, trazem à cena diferentes ocorrências que, na maioria das vezes, serão motivadoras de "novos" trabalhos. 
Estudos em Jornalismo e Mídia - Vol. $10 \mathrm{~N}^{\circ} \mathrm{I}$ - Janeiro a Junho de 2013

\section{Referências Bibliográficas}

AUGUSTINI, Carmen. (N)as dobraduras do dizer e (n)o não-um do sentido e do sujeito: um efeito da presença do interdiscurso no intradiscurso. In: INDURKY, Freda e FERREIRA, Maria Cristina Leandro (org). Análise do discurso no Brasil: mapeando conceitos, confrontando limites. São Paulo: Claraluz, 2007, p. 3003-312.

BENETTI, Márcia. Análise do discurso em jornalismo: estudo de vozes e sentidos. In: LAGO, Cláudia \& BENETTI, Márcia (orgs.). Metodologia de pesquisa em jornalismo. Petrópolis, RJ: Vozes, 2007.

BRASIL. Ministério da Educação. Banco de Teses da Capes. Disponível em: $<$ http://capesdw.capes.gov.br/capesdw>. Acesso em: 20 jul. 2012.

COIMBRA, Fábio Magrinelli. O Ministério Público como defensor do povo no estado democrático de direito brasileiro. 2007. 174 p. Dissertação (Mestrado em Direito) - Faculdade de Direito de Campos, Rio de Janeiro, 2007. Disponível em: <http://capesdw.capes.gov.br/capesdw/resumo.html? idtese $=20073731054013002 \mathrm{P} 9>$. Acesso em: 10 nov. 2010 .

COSTA, Caio Túlio. Ombudsman: o Relógio de Pascal. $2^{\mathrm{a}}$. Ed. rev. e atual. com dois capítulos completamente novos. - São Paulo: Geração editorial, 2006.

DEMO, Pedro. Metodologia científica em ciências sociais. São Paulo: Ática, 2009.

FOUCAULT, Michel. A arqueologia do saber. Trad. Luiz Felipe Baeta Neves. 7 edição. Rio de Janeiro: Forense Universitária, 2007.

GOMES, Manoel Eduardo Alves Camargo e. O regime jurídico das ouvidorias públicas brasileiras: causalidade de sentido e adequação estruturo-funcional. 2000. 511 p.Tese (Doutorado em Direito) Universidade Federal de Santa Catarina, Florianópolis, 2000. Disponível em: $<$ http://capesdw.capes.gov.br/capesdw/resumo.html?idtese=200013841001010011P1 > . Acesso em: 7 abr. 2011.

LAROCCA Maria Teresa Grimaldi. Análise da inserção estratégica do ombudsman na relação da empresa e seus públicos. 2004. 252 p. Dissertação (Mestrado em Administração) - Pontifícia Universidade Católica de São Paulo, São Paulo, 2004. Disponível em: $<$ http://capesdw.capes.gov.br/capesdw/resumo.html?idtese=200439333005010017P2 >. Acesso em: 20 jul. 2010 .

LEITE, Celso Barroso. Ombudsman -Corregedor Administrativo: a instituição escandinava que o mundo vem adotando. Rio de Janeiro: Zahar Editores, 1975.

MELO, Jose Marques e CARVALHO, Samantha Viana Castelo Branco Rocha (ORG). Octávio Frias de Oliveira: 40 anos de liderança no Grupo Folha São Paulo: Uni-FIAMFAAM/ FACOM, 2002.

MAINGUENEAU, Dominique. Gênese dos Discursos. Trd. Sírio Possenti. São Paulo: Parábola Editorial, 2008.

MAZIÈRE, Francine. A análise do discurso: história e práticas. Trad. Marcos Marcionilo. São Paulo: Parábola, 2007.

MOREIRA, Paulo da Veiga. Ouvidoria pública: democracia e direitos fundamentais. 2009. 129 p.

Dissertação (Mestrado em Direito) - Faculdade de Direito de Vitória, Vitória, 2009. Disponível em: $<$ http://capesdw.capes.gov.br/capesdw/resumo.html?idtese=20091830010012001P7> . Acesso em: 20 jul. 2010 .

NASSIF, Gustavo Costa. Ouvidorias públicas: instrumento de aprimoramento da democracia. 2007. 185 p. Dissertação (Mestrado em Direito) - Pontifícia Universidade Católica de Minas Gerais, Belo Horizonte, 2007. Disponível em: $<$ http://capesdw.capes.gov.br/capesdw/resumo.html? $\underline{\text { idtese }=20074732008015005 \mathrm{P} 7>}$. Acesso em: $18 \mathrm{dez} .2010$. 
Estudos em Jornalismo e Mídia - Vol. $10 \mathrm{~N}^{\circ} \mathrm{I}$ - Janeiro a Junho de 2013

ORLANDI, Eni P. Interpretação: autoria, leitura e efeitos do trabalho simbólico. Petrópolis: Vozes, 1996.

PARISI, Celio. A defesa do erário através da ação civil pública e a legitimidade do Ministério Público. 2001. 193 p. Dissertação (Mestrado em Direito) - Instituição Toledo de Ensino, São Paulo, 2001. Disponível em: $<$ http://capesdw.capes.gov.br/capesdw/resumo.html?

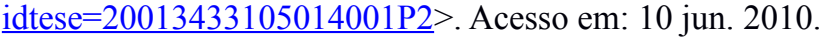

PASCHOAL, Engel. A trajetória de Octávio Frias de Oliveira. 2 Edição. São Paulo: PubliFolha, 2007.

PÊCHEUX, Michel. Semántica e discurso: uma crítica à afirmação do óbvio. Trad. Eni P. Orlandi [et al] 2 ed. Campinas: Editora da Unicamp, 1995.

PILAGALlO, Oscar. O Brasil em destaque: 80 anos de História contados pela Folha. São Paulo: PubliFolha, 2002.

ROCHA, Donatila Brasil. A comunicação com os públicos estratégicos em organizações de capital aberto: o papel do ombudsman e do profissional de relações com investidores. 2007. 107 p. Dissertação. (Mestrado em Administração) - Universidade Católica de Santos, Santos, 2007. Disponível em: $<$ http://capesdw.capes.gov.br/capesdw/resumo.html?idtese=2007533020019002P3>. Acesso em: 20 jun. 2011.

RULLI NETO, Antonio. Controle externo do Poder Judiciário no Brasil. 2007. 312 p. Tese. (Doutorado em Direito) - Universidade de São Paulo, São Paulo, 2007. Disponível em: $<$ http://capesdw.capes.gov.br/capesdw/resumo.html?idtese=20074633002010119P7>. Acesso em: 5 jul. 2011.

SANTOS, Boaventura de Souza. Ciência e Senso Comum. In: Introdução a uma ciência pós-moderna. Rio de Janeiro: Graal, 1989.

SILVA, Carlos Eduardo Lins da. Mil dias: os bastidores da revolução em um grande jornal. Primeira edição. São Paulo: Trajetória Cultural, 1988.

Este artigo e todo o conteúdo da Estudos em Jornalismo e Mídia estão disponíveis em http://www.periodicos.ufsc.br/index.php/jornalismo/index

Estudos em Jornalismo e Mídia está sob a Licença CreativeCommons 